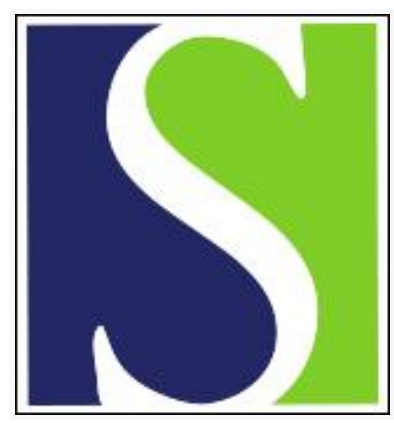

Scand J Work Environ Health 2017;43(5):485-493

https://doi.org/10.5271/sjweh.3638

Published online: 31 Mar 2017, Issue date: 01 Sep 2017

\title{
Shift work and cognitive aging: a longitudinal study
}

by Bokenberger K, Ström P, Dahl Aslan AK, Åkerstedt T, Pedersen NL

$\overline{\text { Shift work, which interferes with circadian rhythms, has evident acute }}$ effects on cognitive performance; however, its long-term impact on cognitive development remains unclear. This longitudinal study concluded shift work during midlife impacts neither cognitive performance at retirement nor cognitive trajectories across late life.

Affiliation: Department of Medical Epidemiology and Biostatistics, Karolinska Institutet, 17177 Stockholm, Sweden. kathleen.bokenberger@ki.se

Refers to the following text of the Journal: 1999;25(6):610-615

The following article refers to this text: 2017;43(6):569-577

Key terms: ageing; aging; cognitive functioning; cognitive performance; growth curve modeling; longitudinal study; night shift work; retirement; shift work; shift worker

This article in PubMed: www.ncbi.nlm.nih.gov/pubmed/28362457

\section{Additional material}

Please note that there is additional material available belonging to this article on the Scandinavian Journal of Work, Environment \& Health -website. 


\title{
Shift work and cognitive aging: a longitudinal study
}

\author{
by Kathleen Bokenberger, MSc, ${ }^{1}$ Peter Ström, MSc, ${ }^{1}$ Anna K Dahl Aslan, PhD, ${ }^{1,2}$ Torbjörn Åkerstedt, \\ PhD, 3,4 Nancy L Pedersen, PhD ${ }^{1,5}$
}

\begin{abstract}
Bokenberger K, Ström P, Dahl Aslan AK, Åkerstedt T, Pedersen NL. Shift work and cognitive aging: a longitudinal study. Scand J Work Environ Health. 2017;43(5):485-493. doi:10.5271/sjweh.3638
\end{abstract}

\begin{abstract}
Objectives The few studies of shift work and late life cognitive functioning have yielded mixed findings. The aim of the present study is to estimate the association between shift-work experience and change in cognitive performance before and after retirement age among older adults who were gainfully employed.

Methods Five hundred and ninety five participants with no dementia were followed up for a mean of 17.6 standard deviation (SD) 8.8 years from a Swedish population-based sample. Participants had self-reported information on any type of shift-work experience (ever/never) in 1984 and measures of cognitive performance (verbal, spatial, memory, processing speed, and general cognitive ability) from up to 9 waves of cognitive assessments during 1986-2012. Night work history (ever/never) from 1998-2002 was available from a subsample (N=320). Early adult cognitive test scores were available for 77 men.

Results In latent growth curve modeling, there were no main effects of "any-type" or night shift work on the mean scores or rate of change in any of the cognitive domains. An interaction effect between any-type shift work and education on cognitive performance at retirement was noted. Lower-educated shift workers performed better on cognitive tests than lower-educated day workers at retirement. Sensitivity analyses, however, indicated that the interactions appeared to be driven by selection effects. Lower-educated day workers demonstrated poorer cognitive ability in early adulthood than lower-educated shift workers, who may have selected jobs entailing higher cognitive demand.
\end{abstract}

Conclusion There was no difference in late-life cognitive aging between individuals with a history of working shifts compared to those who had typical day work schedules during midlife.

Key terms ageing; cognitive functioning; cognitive performance; growth curve modeling; night shift work; retirement; shift worker.

Shift work involves a work schedule that comprises recurring periods of nonstandard work hours compared to a fixed daily work schedule with standard day work hours $(1,2)$. Shift work can encompass early-morning, afternoon, evening or night shifts and be on fixed or rotational (eg, rotating between mornings, afternoons, and nights) schedules (2). The fifth European working conditions survey reported that $17 \%$ of the working population in Europe (3) and 22\% in Sweden (4) are involved in some type of shift work.
Shift work, particularly the type involving working at night, is associated with circadian rhythm disruption that manifests in the form of having trouble falling asleep, shortened sleep, and daytime fatigue $(2,5,6)$. It has also been demonstrated that shift work $(7,8)$ and disturbed sleep (9) result in immediate subsequent decreases in cognitive performance. Displaced work hours may change lifestyle factors, which could play a role in the pathway between shift work and cognitive function $(1,10)$. It is plausible that there may be chronic

\footnotetext{
1 Department of Medical Epidemiology and Biostatistics, Karolinska Institutet, Stockholm, Sweden.

2 Institute of Gerontology, School of Health and Welfare, Jönköping University, Jönköping, Sweden.

3 Stress Research Institute, Stockholm University, Stockholm, Sweden.

4 Department of Clinical Neuroscience, Karolinska Institutet, Stockholm, Sweden.

5 Department of Psychology, University of Southern California, Los Angeles CA, USA.
}

Correspondence to: Kathleen Bokenberger, Department of Medical Epidemiology and Biostatistics, Karolinska Institutet, 17177 Stockholm, Sweden. [E-mail: kathleen.bokenberger@ki.se] 
effects due to prolonged exposure of working the shift schedule. Yet, the effects of shift work on cognition years later are less clear.

Rouch and colleagues (11) were the first to examine this avenue of research based on a cross-sectional sample of 3237 French salaried workers from the VISAT study on aging, health and work. Among men only, it was observed that current or previous exposure to any atypical work schedule was associated with lower global cognitive performance scores compared to no shift work exposure and that duration of shift work experience spanning 10-20 years was related to poorer memory performance than having 1-4 years shift work experience (11). A prospective cohort study based on the same French cohort observed that any type of atypical work schedule versus normal work schedules, as well as duration of $>10$ years compared to fewer years of rotating shift work, were associated with lower scores on global cognitive performance and composite memory and speed performance. The study also reported that former shift workers who ceased working shifts within the past five years demonstrated recovery of cognitive functioning (12). Similarly, a cross-sectional Swedish study reported that current and past shift workers performed worse on the Trail Making Test of processing speed and executive cognitive function compared to ever day workers, and that performance did not differ between day- and shift workers who had quit shift work for $>5$ years (13). The Nurses' Health Study, which has been the only study examining shift work in relation to cognitive change over time, followed 16190 female participants over a 6-year period with three repeated cognitive assessments. The study found little evidence of midlife rotating night shift work to have an effect on mean cognition and cognitive decline rates (10). Impact of shift work on cognitive change over a longer period of time is unknown. Higher educational attainment is a strong predictor of cognitive ability and has been hypothesized to provide cognitive reserve and to compensate for cognitive deficits seen in normative aging (14), but research on interactive influences of education with shift work on cognition is lacking. The Nurse's Health Study was restricted to highly educated participants who held at least a registered nurse or bachelor's degree (10), and the more recent French study did not account for educational differences in their analyses.

Given the mixed findings reported from the few studies on shift work in relation to cognitive performance and cognitive change over a time period $>6$ years, the present study aims to estimate the association of "anytype" shift work and night shift work experience with rate of change in cognitive functioning over the course of 27 years among older adults who were at some point gainfully employed.

\section{Methods}

\section{Participants}

Participants were enrolled in the Swedish Adoption Twin Study of Aging (SATSA), which has been described in detail previously $(15,16)$. In short, the sample was drawn from the population-based Swedish twin registry (17) and comprises a questionnaire component that began with a baseline questionnaire in 1984 and an in-person testing (IPT) component (18). Twins who responded to the questionnaire in 1984 and who were $\geq 50$ years of age were eligible for IPT inclusion. IPT involved an extensive cognitive assessment that began in 1986 of a subsample of twins $\geq 50$ years of age. All previous IPT participants, as well as twins who had responded to the baseline questionnaire and had reached 50 years of age since the last IPT, were invited to participate in subsequent IPT up to IPT9. Data have been collected on up to 9 occasions at approximately rolling 3-year intervals between 1986-1992 and 1999-2012. There were 645 twins who participated in the first IPT, and 859 twins who participated in $\geq 1$ of 9 possible IPT waves. The study has a high response rate with an average of $\geq 90 \%$ returning participants for each IPT wave.

Suspected dementia cases and their co-twins were referred to a complete clinical workup. Clinical diagnoses of dementia were based on current diagnostic criteria and were determined during a consensus conference that included a review of cognitive test scores, health and daily functioning, and medical records $(19,20)$. For participants who developed dementia $(\mathrm{N}=46)$, data points after the dementia diagnosis were excluded. Thus, the trajectories include preclinical changes, but not those subsequent to a clinical diagnosis.

Of the 859 who participated in an IPT assessment, we excluded those (i) with missing data on work during the greater part of one's life - most of whom were housewives $(\mathrm{N}=236)$ - and occupational status $(\mathrm{N}=18)$, (ii) who never reached 50 years of age during the time they were in the study ( $\mathrm{N}=2)$, (iii) who retired during young adulthood $(\mathrm{N}=1)$ and (iv) those with dementia diagnoses at the first IPT assessment $(\mathrm{N}=7)$. Our study resulted in an analytic sample of 595 participants.

Of these, a subsample of 320 participants born 1958 or earlier had data on night work that was assessed via a computer-assisted telephone interview during 1998 to 2002 in the Swedish Screening Across the Lifespan Twin study (SALT) (17). Another subsample of 77 men had data on early adult general cognitive ability from the Swedish Military Service Conscription Register (21). Participants gave informed consent, and the Regional Ethical Review Board at Karolinska Institutet, Stockholm, approved the data collection (Dnr 80:80, 84:61, 98:319, and 2007/151-31/4). 


\section{Cognitive measures}

Four cognitive domains were assessed based on the cognitive battery in SATSA: verbal, memory, spatial abilities, and processing speed $(22,23)$. Verbal abilities were assessed by tests for information and synonyms, memory by tests for digit span, picture memory, and names and faces exercises, spatial abilities by tests for figure logic, block design, and card rotations tests, and processing speed by the symbol digit and figure identification tests (23). A general cognitive ability measure was created based on performance scores from all subtests. Latent components for each of the five cognitive measures based on scores from the relevant cognitive test were computed using principal component analysis, described elsewhere (24).

Early adult general cognitive ability data from the Swedish Conscription Register were based on four subtests (verbal, spatial, logical, and technical ability) that were given to SATSA men 18 years of age born between 1936-1948 who were conscripted for the military service. A general cognitive ability score was created by summing the normalized $\mathrm{z}$ scores of the four tests, yielding a score ranging $1-40$ points, with a higher score indicating higher cognitive ability (25).

\section{Shift work measures}

Data on shift work and other covariates was collected from the SATSA baseline questionnaire mailed out in 1984. Participants who indicated they worked shifts for the greater part of their life and/or in the last 12 months were considered as having shift work history (grouped as ever/never). Shift work was measured only at baseline and was not defined in the questionnaire. A shift work duration measure with four categories was also created $(0,1-9,10-19, \geq 20$ years $)$ and is comparable to the shift work duration measure used in the Nurses' Health Study (10). A subsample of 320 of the 595 SATSA participants had data on night work measured in SALT in 1998-2002. The night work measure (grouped as ever/ never) was based on the item from the SALT questionnaire: "During about how many years have you had working hours that meant that you at least sometimes worked at night?"

\section{Covariates}

Information on age and sex were from the Swedish twin registry. Educational attainment (grouped as elementary school education and education beyond elementary school) data came from the baseline questionnaire. Other covariates obtained from the baseline questionnaire included: (i) occupational status (grouped as manual and non-manual work based on self-reported occupa- tion one had for the major part of one's working life), (ii) smoking (current smokers grouped as smokers, non-smokers and ex-smokers grouped as non-smokers), (iii) alcohol consumption (yes/no alternatives), (iv) difficulty falling asleep (yes/no alternatives), and (v) sleep medication use (yes/no alternatives). Multiple waves of data were available for smoking and sleep medication use (seven waves between 1984-2010) and alcohol consumption (three waves between 1984-1990). Leisure-time exercise (grouped as "hardly any exercise", "very little to a little exercise", and "quite much to very much exercise") was measured via questionnaires from 1990-2010. Body mass index (BMI) was objectively measured at all nine IPT waves and was categorized as follows: underweight, normal weight, and overweight/ obese $\left(<20,20-25,>25 \mathrm{~kg} / \mathrm{m}^{2}\right.$, respectively). A measure for work complexity was derived from an item asking about the occupation he/she had for the greater part of his/her working life coded to the Swedish Standard for Classification of Occupations. The complexity of work scores ranged from $0-10$, with higher scores reflecting greater complexity (26).

\section{Retirement age}

In order to capture performance change before and after retirement, we need to estimate the performance score at retirement age. Centering age was set at each participant's retirement age. Retirement age was calculated by taking the difference between the last self-reported retirement year and birth year. Those who did not report a retirement year were given an estimated retirement age of $65(\mathrm{~N}=46)$, the national retirement age in Sweden (27). Of these individuals, 14 [mean age at last IPT visit 67.8 (SD) 2.4 years] had turned 65 years old during the course of follow-up, and 32 [mean age at last IPT visit 59.7 (SD) 3.7 years] had not.

\section{Statistical methods}

Latent growth curve modeling (LGCM) was used to assess the association of shift work with cognitive functioning at retirement and across the life course. LGCM is composed of fixed effects, represented by the mean intercept at age of retirement and slope estimates used to construct trajectories of cognition over time, and random effects, which account for repeated measurements within subjects.

First, a two-slope model was determined to be best fitting for all cognitive factors as indicated by smaller Akaike information criterion (AIC) fit estimates. The model included an intercept and two slopes [slope 1 (S1) and slope 2 (S2)]. The intercept is at retirement age, which was set as centering age. S1 was defined as the rate of cognitive change per year spanning across 
the entire measurement period. S2 was defined as the additional rate of cognitive change per year after retirement age.

Next, the binary shift work (ever/never) measure at baseline, treated as a fixed measure, was included as the main effect in the two-slope model. Fixed covariates for duration of shift work experience, difficulty falling asleep, and work complexity as well as time-varying covariates for smoking, alcohol use, BMI, sleep medication use, and leisure-time exercise were considered, but ultimately dropped from the final models as inclusion of these covariates did not influence the point estimates or improve the model fit. Final models were adjusted for baseline age, sex, education, and occupational status as well as an interaction term for shift work and education (interaction term $\mathrm{P}<0.05$ ). Within the models, interaction terms of all covariates with both slopes (variable $\times \mathrm{S} 1$ and variable $\times$ S2) were included, thereby allowing for cognitive change to vary as a function of the covariates.

The association between shift work duration and cognitive functioning was analyzed separately in a different model adjusted for baseline age, sex, education, and occupational status. Sensitivity analyses were performed to examine: (i) the effect of night work on level and change of cognitive performance based on a subset of participants $(\mathrm{N}=320)$, and (ii) the possibility of selection effects by comparing mean early adult cognitive scores between shift- and day workers by low and high educational attainment on a subsample of males $(\mathrm{N}=77)$.

All models accounted for relatedness of twin members by including a variable that indicates pair membership in the random statement. An alpha level of 0.05 was consistently used as the significance level for all tests. LGCM analyses were performed using Proc Mixed and the figure was generated in SAS 9.4 (SAS Institute, Cary NC, USA).

\section{Results}

The mean follow-up time was 17.6 (SD 8.8) years with a range of 0 (for 70 persons who only participated at a single IPT occasion) to 27 years. Of the 595 participants, 120 participated in both the first and last IPT, and 111 persons participated in all IPT excluding IPT4, which was incomplete due to funding reasons. The 70 participants with cognitive measurements at only one time point contribute towards the predicted mean score as well as the predicted mean rate of change in the LGCM. The proportion of shift workers was $17.8 \%$ at baseline, which was the only time shift work was measured. Throughout waves, percentage of shift workers generally remained between 17-20\% (appendix A, www. sjweh.fi/index.php?page=data-repository). A summary of participants' characteristics is presented in table 1 . Participants with a shift work history were more likely to be men, lower educated, manual rather than non-manual workers, and overweight/obese than participants with no shift work history.

\section{Shift work in relation to cognitive performance level and change from LGCM}

Table 2 presents parameter estimates for the intercepts and slopes for each of the five cognitive factors. The intercept value is the mean performance score at retirement age. Age has a significant effect on S2 for verbal ability [estimated mean 0.69 , standard error (SE) 0.28] and on S1 for spatial ability [estimated mean 0.85 (SE) 0.34 ] and global performance [estimated mean 0.57 (SE) 0.24].

We found no evidence of an association of shift work with mean cognitive performance at retirement (intercept) or with cognitive change (S1 and S2). Let us take estimates for verbal ability in table 2 as an example. For day workers (shift work $=0$ ), the predicted mean verbal ability score at retirement was 51.66 , the mean rate of change was -0.04 across the study period, and the additional rate of change after retirement was 0.69. Compared to day workers, shift workers (shift work=1) performed 1.33 points better at retirement (SE 0.86 ), had a mean rate of change difference of 0.04 (SE 0.07 ) across the study period, and additional rate of change difference of -0.12 (SE 0.09) after retirement. These parameters were not significant, meaning that there was no significant association of shift work history with mean performance at retirement or rate of change for verbal ability. This was also the case for the other cognitive factors (table 2).

We also plotted model-based performance scores by shift work status and observed that point estimates centered at retirement age and slopes for shift workers and day-workers were similar (figure 1a-d).

There was no apparent association of duration of shift work with mean cognitive performance and change (appendix B, www.sjweh.fi/index.php?page=datarepository).

Education and occupational status were highly predictive of all cognitive performance factors, but at the intercept only. We observed a 2-way interaction on the intercept (shift work $\times$ education $\times$ intercept), which was particularly pronounced for verbal ability. No interaction was observed on the slopes (shift work $\times$ education $\times$ slope) (results not shown). The lack of interaction on the slopes is demonstrated by the parallel slopes before and after retirement between shift work and education groups for all cognitive factors (figure 1). Shift workers performed worse at retirement age on cognitive tests than day workers among the high education 
Table 1. Characteristics of participants. Variables were measured at baseline unless otherwise specified. [IPT=in-person-testing.]

\begin{tabular}{|c|c|c|c|c|c|c|c|c|c|c|c|c|c|}
\hline & \multicolumn{4}{|c|}{$\begin{array}{c}\text { All } \\
(\mathrm{N}=595)\end{array}$} & \multicolumn{4}{|c|}{$\begin{array}{l}\text { No shift work history } \\
\qquad(\mathrm{N}=489)\end{array}$} & \multicolumn{4}{|c|}{$\begin{array}{l}\text { Shift work history } \\
\quad(N=106)\end{array}$} & \multirow[t]{2}{*}{ P-value a } \\
\hline & $\mathrm{N}$ & $\%$ & Mean & SD & $\mathrm{N}$ & $\%$ & Mean & SD & $\mathrm{N}$ & $\%$ & Mean & SD & \\
\hline Baseline age in 1984 & 595 & & 58.2 & 10.5 & 489 & & 58.4 & 10.5 & 106 & & 57.1 & 10.4 & 0.24 \\
\hline Age at first cognitive assessment & 595 & & 62.6 & 8.5 & 489 & & 62.8 & 8.5 & 106 & & 61.2 & 8.3 & 0.08 \\
\hline Age at retirement & 595 & & 64.1 & 3.2 & 489 & & 64.2 & 3.1 & 106 & & 63.2 & 3.7 & 0.005 \\
\hline Mean number of IPT waves of participation & 595 & & 4.7 & 2.4 & 489 & & 4.6 & 2.4 & 106 & & 4.9 & 2.4 & 0.18 \\
\hline Work complexity ${ }^{b}$ & 595 & & 4.2 & 2.1 & 489 & & 4.3 & 2.1 & 106 & & 3.7 & 3.3 & 0.01 \\
\hline Male & 299 & 50.2 & & & 229 & 46.8 & & & 70 & 66.0 & & & 0.0004 \\
\hline \multicolumn{14}{|l|}{ Highest educational attainment } \\
\hline Elementary education & 319 & 53.6 & & & 249 & 41.9 & & & 70 & 66.0 & & & 0.004 \\
\hline Higher education & 276 & 46.4 & & & 240 & 49.1 & & & 36 & 34.0 & & & \\
\hline \multicolumn{14}{|l|}{ Occupational status } \\
\hline Manual & 310 & 52.1 & & & 259 & 53.0 & & & 68 & 64.2 & & & 0.04 \\
\hline Non-manual & 285 & 47.9 & & & 230 & 47.0 & & & 38 & 35.8 & & & \\
\hline \multicolumn{14}{|l|}{ Duration of shift work } \\
\hline 0 years & 489 & 82.2 & & & 489 & 100 & & & & & & & $<0.0001$ \\
\hline $1-9$ years & 43 & 7.2 & & & & & & & 43 & 40.6 & & & \\
\hline $10-19$ years & 32 & 5.4 & & & . & & & & 32 & 30.2 & & & \\
\hline$\geq 20$ years & 31 & 5.2 & & & . & & & & 31 & 29.2 & & & \\
\hline \multicolumn{14}{|l|}{ Alcohol consumption } \\
\hline No & 147 & 24.7 & & & 129 & 26.4 & & & 18 & 17.0 & & & 0.04 \\
\hline Yes & 448 & 75.3 & & & 360 & 73.6 & & & 88 & 83.0 & & & \\
\hline \multicolumn{14}{|l|}{ Smoking } \\
\hline No & 427 & 71.8 & & & 353 & 72.2 & & & 74 & 69.8 & & & 0.62 \\
\hline Yes & 168 & 28.2 & & & 136 & 27.8 & & & 32 & 30.2 & & & \\
\hline \multicolumn{14}{|l|}{ Difficulty falling asleep } \\
\hline No & 458 & 77.0 & & & 375 & 76.7 & & & 83 & 78.3 & & & 0.80 \\
\hline Yes & 137 & 23.0 & & & 114 & 23.3 & & & 23 & 21.7 & & & \\
\hline \multicolumn{14}{|l|}{ Sleep medication use } \\
\hline No & 541 & 90.9 & & & 441 & 90.2 & & & 100 & 94.3 & & & 0.20 \\
\hline Yes & 54 & 9.1 & & & 48 & 9.8 & & & 6 & 5.7 & & & \\
\hline \multicolumn{14}{|l|}{ Body mass index } \\
\hline Underweight & 31 & 5.2 & & & 30 & 6.1 & & & 1 & 0.9 & & & 0.07 \\
\hline Normal weight & 269 & 45.2 & & & 222 & 45.4 & & & 47 & 44.3 & & & \\
\hline Overweight/obese & 295 & 49.6 & & & 237 & 48.5 & & & 58 & 54.7 & & & \\
\hline \multicolumn{14}{|l|}{ Leisure-time exercise ${ }^{c}$} \\
\hline Hardly any & 38 & 9.0 & & & 28 & 8.3 & & & 10 & 11.9 & & & 0.52 \\
\hline Very little to a little exercise & 213 & 50.5 & & & 173 & 51.2 & & & 40 & 47.6 & & & \\
\hline Quite much to very much exercise & 171 & 40.5 & & & 137 & 40.5 & & & 34 & 40.5 & & & \\
\hline
\end{tabular}

a P-value for t-test or f-test statistic, as appropriate.

b 465 participants had work complexity data, of which 380 did not have shift work history and 85 had shift work history.

c 422 participants had leisure-time exercise data measured in 1990, of which 338 did not have shift work history and 84 had shift work history.

Table 2. Results from growth curve model estimating association of shift work with level and change in cognitive performance ${ }^{a}(\mathrm{~N}=595)$. [SE=standard error].

\begin{tabular}{|c|c|c|c|c|c|c|c|c|c|c|c|}
\hline \multirow[t]{2}{*}{ Effect } & \multirow{2}{*}{$\begin{array}{l}\text { Shift work } \\
\text { history }\end{array}$} & \multicolumn{2}{|c|}{ Verbal } & \multicolumn{2}{|c|}{ Spatial } & \multicolumn{2}{|c|}{ Memory } & \multicolumn{2}{|c|}{ Processing speed } & \multicolumn{2}{|c|}{ Global } \\
\hline & & Estimate & SE & Estimate & SE & Estimate & SE & Estimate & SE & Estimate & SE \\
\hline \multirow[t]{2}{*}{ Intercept $_{\mathrm{RA}}$} & $0=$ No (Reference) & $51.66^{b}$ & 2.16 & $64.66^{b}$ & 2.73 & $50.86^{b}$ & 2.59 & $59.78^{b}$ & 2.49 & $57.99 \mathrm{~b}$ & 2.33 \\
\hline & $1=Y_{e s}{ }^{c}$ & 1.33 & 0.86 & 0.01 & 1.07 & 0.88 & 0.99 & 0.01 & 0.97 & 0.35 & 0.93 \\
\hline \multirow[t]{2}{*}{ Linear $\mathrm{Age}_{\mathrm{S} 1}$} & $0=$ No (Reference) & -0.04 & 0.24 & $0.85^{d}$ & 0.34 & 0.64 & 0.40 & 0.69 & 0.37 & $0.57^{d}$ & 0.24 \\
\hline & $1=Y_{e s}{ }^{e}$ & 0.04 & 0.07 & -0.06 & 0.10 & -0.18 & 0.11 & -0.13 & 0.12 & -0.12 & 0.07 \\
\hline \multirow[t]{2}{*}{ Linear $\mathrm{Age}_{\mathrm{S} 2}$} & $0=$ No (Reference) & $0.69^{c}$ & 0.28 & -0.46 & 0.43 & 0.26 & 0.48 & -0.31 & 0.45 & 0.26 & 0.31 \\
\hline & $1=$ Yes $^{\dagger}$ & -0.12 & 0.09 & 0.12 & 0.14 & 0.29 & 0.15 & 0.21 & 0.14 & 0.20 & 0.10 \\
\hline
\end{tabular}

a All models are adjusted for baseline age, sex, education, and occupational status, but only fixed effects of shift work are presented.

${ }^{b} \mathrm{P}<0.001$.

${ }^{\mathrm{C}}$ Effect of shift work on mean performance level (Intercept $\left.\mathrm{RA}_{\mathrm{AA}}\right)$ at retirement age compared to reference.

${ }^{\mathrm{d}} \mathrm{P}<0.05$

${ }^{e}$ Effect of shift work on rate of change per year in cognitive performance across the entire measurement period (Linear Age ${ }_{S 1}$ ) compared to reference.

${ }^{\dagger}$ Effect of shift work on additional rate of change per year in cognitive performance after retirement age (Linear Age $_{\mathrm{S} 2}$ ) compared to reference. 


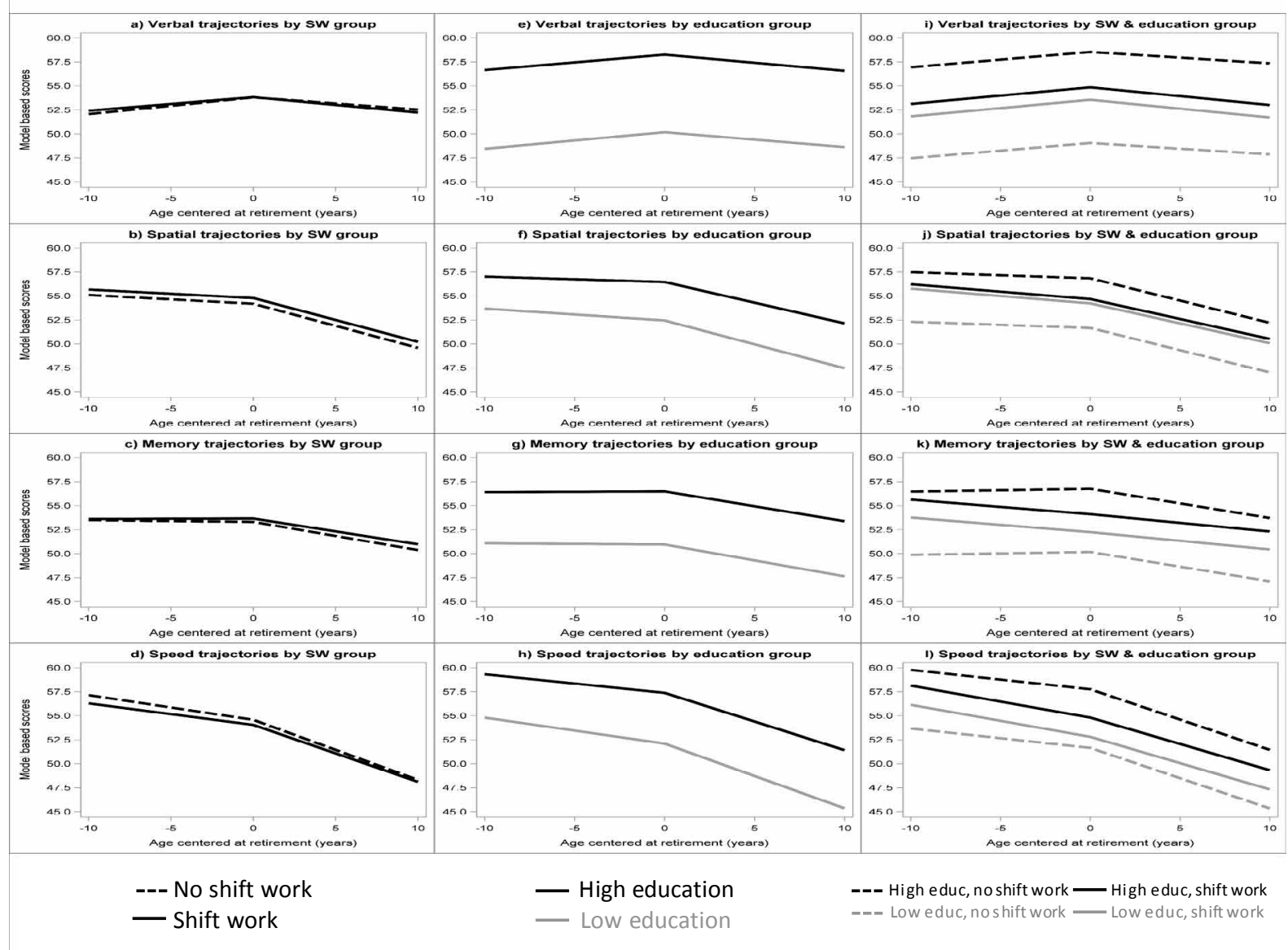

Figure 1. Trajectories of verbal, spatial, memory, and processing speed performance plotted on unadjusted model-based scores at the intercept (retirement age) and at 10 years before and after retirement age by shift work (SW) status (left column), education level (middle column) and SW and education status (right column).

group, but performed better than day-workers among the low education group (figure 1i-1).

\section{Additional analyses}

To further explore the shift work $\times$ education interaction finding, we compared early adult general cognitive ability scores between shift- and day workers within low and high education groups in a subset of 77 men. Among those lower educated $(\mathrm{N}=33)$, the mean early adult cognitive score was higher for shift workers $(\mathrm{N}=8$, mean 19.4, SD 5.4) than for day workers ( $\mathrm{N}=25$, mean 16.8, SD 5.3) (F-statistic $=1.5, \mathrm{DF}=1, \mathrm{P}=0.23$ ). In those with higher education $(\mathrm{N}=44)$, the early adult cognitive scores were slightly lower among shift- than day workers $(\mathrm{N}=10$, mean 19.5, SD 5.6; $\mathrm{N}=34$, mean 22.0, SD 5.23, respectively) ( $F$-statistic $=1.7, D F=1, P=0.20$ ). The lack of significance likely reflects the analysis being under-powered.

In sensitivity analyses based on a subset $[\mathrm{N}=320$; mean baseline age 55.0 (SD) 8.8 years] of which 106 were shift-workers and 47 of the 320 individuals (14.7\%) of these worked night shifts, we analyzed the association between night work and cognition. All 47 night shiftworkers based on SALT data had also responded that they were shift workers in SATSA. The mean age at the time of response to the SALT questionnaire in 1998-2002 for this subsample was 69.2 (SD 8.7) years. No impact of night work on the predicted mean or change in cognitive performance was found (appendix C, www.sjweh.fi/index.php?page=data-repository. Similarly to the shift work $\times$ education interaction effect on the intercept, a two-way interaction on the intercept (night work $\times$ education $\times$ intercept) for verbal ability and global cognitive performance was observed (appendix D, www.sjweh.fi/index.php?page=data-repository).

\section{Discussion}

In our study based on a Swedish cohort of middle to older aged adults, midlife shift work was not associ- 
ated with mean cognitive performance at retirement age or with rate of cognitive change during the 27-year follow-up period for any of the cognitive factors (verbal, spatial, memory, processing speed, and general cognitive ability).

The lack of evidence of an association of shift work with cognitive level and change agrees with what has been reported in the Nurse's Health Study (10), but not with that in other studies $(12,28)$. Marquie et al (12) observed shift work to be prospectively associated with poorer memory and speed performance and was the first study to report that cognitive performance did not differ between day workers and former shift workers who had left shift work for $\geq 5$ years. A concern is that those who had left shift work $>5$ years ago may have exhibited higher cognitive ability and therefore had more opportunities to change work than recent former and current shift workers. However, education, which is generally a strong indicator of cognitive ability, was not adjusted for in the study's analyses. Further, the study would have benefited from a within-subjects design which would have allowed for detection of within-subject cognitive change rather than between-subject cognitive differences. In contrast, our study controlled for educational differences and employed an intra-individual approach to assess the association between shift work and cognition, which altogether may have led to diverging findings. Titova et al (28) similarly reported that shift work was associated with poorer executive cognitive function, though the cross-sectional study design and not accounting for neurodegenerative disease suggest findings should be interpreted cautiously. The present study's findings together with those of the Nurse's Health Study (10) lead to the conclusion that there is no association of shift work with cognitive ability and change.

Education was robustly associated with cognitive function at retirement, particularly verbal ability, which is not surprising as verbal skills are highly dependent on education level (29). The inclusion of the interaction term for education with shift work in the model yielded an unexpected finding such that lower-educated shift workers performed better on cognitive tests than lowereducated day workers at retirement. A similar interaction effect of night work and education on verbal ability performance at retirement was noted. We hypothesized that within the pool of jobs available for persons with low education, shift work jobs such as working as a railway conductor may have required greater cognitive ability compared to work with daytime work hours such as a salesclerk job. This in turn may have led to selection effects in our sample. Indeed, sensitivity analyses showed that, among those with lower educational attainment, shift workers demonstrated greater cognitive ability during young adulthood than day workers. The opposite association was seen among those with higher educational attainment. However, there were no differences in the trajectories of cognitive abilities between these groups, again demonstrating a lack of association between shift work and cognitive aging.

\section{Limitations and strengths}

A limitation of this study is that the shift work measure used in the full analytic cohort did not differentiate between shift work schedules with, for example, early morning, evening, or night shifts and whether the shifts were on permanent or rotational schedules. Given that a meta-analysis found little evidence that fixed night shift workers demonstrated sufficiently beneficial circadian adjustment to the imposed shift schedule when compared to rotating shift work (30), the non-differentiation of shift work types may be negligible. Moreover, additional subanalyses assessing cognitive functioning in relation to night shift work, a more sensitive measure for capturing potential circadian rhythm interference since night work displaces sleep to daytime (31), yielded similar null findings. Misclassification of shift work exposure, ie, from changing from shift work to day-work or vice versa, is possible since shift work status was based on one baseline measurement and treated as a fixed exposure, which may have biased results toward the null. However, based on the subsample analysis of 320 participants who had information on night work, everyone who responded that they had worked nights in 1998-2002 had also responded they worked shifts at baseline in 1984, which suggests data are sound. Self-reporting of shift work experience may have led to underreporting. Still, the proportion of any-type shift workers (18\%) and night shift workers $(14.7 \%)$ in the present study is comparable to the $17 \%$ figure in the Swedish population during the 1980s (32). Another caveat with this study was that there was no information on the amount of time elapsed between shift work cessation and first cognitive testing. We therefore cannot rule out the possibility of shift work having an acute impact on cognition soon after shift work exposure. A strength of this study is our population-based sample with up to nine objective assessments of cognitive performance over 27 years, which is, to the best of our knowledge, the longest longitudinal study on shift work and late life cognition. The composite cognitive measures in this study have been used in previous work (26) and were based on various tests of cognitive ability with reliabilities ranging $0.82-0.96(15)$. The study design is appropriate for assessing the causal influence of shift work on cognitive aging. Unlike the Nurse's Health Study (10), our study included both men and women who had heterogeneous distributions of education levels, thereby not limiting the generalizability of the findings. 


\section{Concluding remarks}

In summary, those with a history of working any type of shift work or specifically night shift work compared to those who had typical day-work schedules in midlife did not differ in late life normative cognitive aging. While research points to shift work having clear acute effects on cognitive performance, shift work does not appear to have cognitive influences lasting into late adulthood. Future studies investigating the association between shift work and cognitive aging should pay heed to potential worker selection effects and include multiple measurements of shift work and cognitive performance over a long follow-up time.

\section{Funding}

This work was supported by grants from the National Institute on Aging (AG04563 and AG10175) and the Swedish Research Council for Health, Working Life and Welfare (FORTE) (grant number 2013-2292).

\section{Conflict of interest}

The authors declare no conflicts of interest.

\section{References}

1. Wang XS, Armstrong ME, Cairns BJ, Key TJ, Travis RC. Shift work and chronic disease: the epidemiological evidence. Occup Med (Lond). 2011;61(2):78-89. https://doi. org/10.1093/occmed/kqr001.

2. Akerstedt T. Shift work and disturbed sleep/wakefulness. Occup Med. 2003;53(2):89-94. https://doi.org/10.1093/ occmed/kqg046.

3. Eurofound. Fifth European Working Conditions Survey. Publications Office of the European Union, Luxembourg. 2012.

4. Statistics Sweden. Living Conditions Surveys, distribution of working hours for employees aged 16-64. Proportion of persons in percent by indicator, level of education, sex and period. Available from: http://www.statistikdatabasen.scb. se/pxweb/en/ssd/START_LE_LE0101_LE0101S/ LE01012013A22/table/tableViewLayout 1/?rxid=94241e6eb81c-48a1-abcf-301307e08b9b. [Accessed September 8, 2015].

5. Akerstedt T, Nordin M, Alfredsson L, Westerholm P, Kecklund G. Sleep and sleepiness: impact of entering or leaving shiftwork--a prospective study. Chronobiol Int. 2010;27(5):987-96. https://doi.org/10.3109/07420528.2010 .489423 .

6. Härmä MI, Ilmarinen JE. Towards the 24-hour society - new approaches for aging shift workers? Scand J Work Environ Health. 1999(6):610-5. https://doi.org/10.5271/sjweh.488.

7. Ozdemir PG, Selvi Y, Ozkol H, Aydin A, Tuluce Y, Boysan
$\mathrm{M}$, et al. The influence of shift work on cognitive functions and oxidative stress. Psychiatry Res. 2013;210(3):1219-25. https://doi.org/10.1016/j.psychres.2013.09.022.

8. Machi MS, Staum M, Callaway CW, Moore C, Jeong K, Suyama J, et al. The relationship between shift work, sleep, and cognition in career emergency physicians. Acad Emerg Med. 2012;19(1):85-91. https://doi.org/10.1111/j.15532712.2011.01254.x.

9. Blackwell T, Yaffe K, Ancoli-Israel S, Schneider JL, Cauley JA, Hillier TA, et al. Poor sleep is associated with impaired cognitive function in older women: the study of osteoporotic fractures. J Gerontol A Biol Sci Med Sci. 2006;61(4):405-10. https://doi.org/10.1093/gerona/61.4.405.

10. Devore EE, Grodstein F, Schernhammer ES. Shift work and cognition in the Nurses' Health Study. Am J Epidemiol. 2013;178(8):1296-300. https://doi.org/10.1093/aje/kwt214.

11. Rouch I, Wild P, Ansiau D, Marquié J-C. Shiftwork experience, age and cognitive performance. Ergonomics. 2005;48(10):1282 93. https://doi.org/10.1080/00140130500241670.

12. Marquie JC, Tucker P, Folkard S, Gentil C, Ansiau D. Chronic effects of shift work on cognition: findings from the VISAT longitudinal study. Occup Environ Med. 2015;72(4):258-64. https://doi.org/10.1136/oemed-2013-101993.

13. Titova $\mathrm{OE}$, Lindberg E, Elmståhl S, Lind L, Schiöth HB, Benedict C. Association between shift work history and performance on the trail making test in middle-aged and elderly humans: the EpiHealth study. Neurobiol Aging. 2016;45:23-9. https://doi.org/10.1016/j.neurobiolaging.2016.05.007.

14. Scarmeas N, Stern Y. Cognitive Reserve: Implications for Diagnosis and Prevention of Alzheimer's Disease. Curr Neurol Neurosci Rep. 2004;4(5):374-80. https://doi.org/10.1007/ s11910-004-0084-7.

15. Finkel D, Pedersen NL. Processing Speed and Longitudinal Trajectories of Change for Cognitive Abilities: The Swedish Adoption/Twin Study of Aging. Aging Neuropsych Cognition. 2004;11(2-3):325-45. https://doi. org/10.1080/13825580490511152.

16. Pedersen NL, McClearn GE, Plomin R, Nesselroade JR, Berg S, DeFaire U. The Swedish Adoption Twin Study of Aging: an update. Acta Genet Med Gemellol (Roma). 1991;40(1):7-20. https://doi.org/10.1017/S0001566000006681.

17. Lichtenstein P, De faire U, Floderus B, Svartengren M, Svedberg P, Pedersen NL. The Swedish Twin Registry: a unique resource for clinical, epidemiological and genetic studies. J Intern Med. 2002;252(3):184-205. https://doi. org/10.1046/j.1365-2796.2002.01032.x.

18. Schmutte T, Harris S, Levin R, Zweig R, Katz M, Lipton R. The relation between cognitive functioning and self-reported sleep complaints in nondemented older adults: results from the Bronx aging study. Behav Sleep Med. 2007;5(1):39-56. https://doi.org/10.1207/s15402010bsm0501_3.

19. Gatz M, Pedersen NL, Berg S, Johansson B, Johansson K, Mortimer JA, et al. Heritability for Alzheimer's disease: the study of dementia in Swedish twins. J Gerontol A Biol Sci Med Sci. 1997;52(2):M117-125. https://doi.org/10.1093/ gerona/52A.2.M117. 
20. Bokenberger K, Pedersen NL, Gatz M, Dahl AK. The type A behavior pattern and cardiovascular disease as predictors of dementia. Health Psychol. 2014;33(12):1593-601. https://doi. org/10.1037/hea0000028.

21. Ludvigsson JF, Andersson E, Ekbom A, Feychting M, Kim $\mathrm{JL}$, Reuterwall $\mathrm{C}$, et al. External review and validation of the Swedish national inpatient register. BMC Public Health. 2011;11:450. https://doi.org/10.1186/1471-2458-11-450.

22. Nesselroade JR, Pedersen NL, McClearn GE, Plomin R, Bergeman CS. Factorial and criterion validities of telephoneassessed cognitive ability measures. Age and gender comparisons in adult twins. Res Aging. 1988;10(2):220-34. https://doi.org/10.1177/0164027588102004.

23. Pedersen NL, Plomin R, Nesselroade JR, McClearn GE. A Quantitative Genetic Analysis of Cognitive Abilities During the Second Half of the Life Span. Psych Sci. 1992;3(6):34653. https://doi.org/10.1111/j.1467-9280.1992.tb00045.x.

24. Finkel D, Reynolds CA, McArdle JJ, Pedersen NL. The longitudinal relationship between processing speed and cognitive ability: genetic and environmental influences. Behavior genetics. 2005;35(5):535-49. https://doi. org/10.1007/s10519-005-3281-5.

25. Nordström P, Nordström A, Eriksson M, Wahlund L, Gustafson Y. Risk factors in late adolescence for youngonset dementia in men: A nationwide cohort study. JAMA Int Med. 2013;173(17):1612-8. https://doi.org/10.1001/ jamainternmed.2013.9079.

26. Finkel D, Andel R, Gatz M, Pedersen NL. The role of occupational complexity in trajectories of cognitive aging before and after retirement. Psychol Aging. 2009;24(3):56373. https://doi.org/10.1037/a0015511.
27. OECD. Ageing and Employment Policies - Statistics on average effective age of retirement: Average effective age of retirement in 1970-2014 in OECD countries. Available from: http://www.oecd.org/els/public-pensions/ ageingandemploymentpolicies-statisticsonaverageeffective ageofretirement.htm. [Accessed January 24, 2017].

28. Titova OE, Lindberg E, Elmstahl S, Lind L, Schioth HB, Benedict C. Association between shift work history and performance on the trail making test in middle-aged and elderly humans: the EpiHealth study. Neurobiol Aging. 2016;45:23-9. https://doi.org/10.1016/j.neurobiolaging.2016.05.007.

29. Alwin DF, McCammon RJ. Aging, Cohorts, and Verbal Ability. J Geront Series B: Psychcol Sci Soc Sci. 2001;56(3):S151S161. https://doi.org/10.1093/geronb/56.3.S151.

30. Folkard S. Do permanent night workers show circadian adjustment? A review based on the endogenous melatonin rhythm. Chronobiol Int. 2008;25(2):215-24. https://doi. org/10.1080/07420520802106835.

31. Riemann D. Nonrestorative Sleep: A New Perspective. Sleep. 2013;36(5):633-4. https://doi.org/10.5665/sleep.2612.

32. Employment, working hours and work environment 20022003. Örebro: Statistics Sweden; 2005. p37.

Received for publication: 5 December 2016 